\title{
EM DEFESA DA DIGNIDADE: MORALIDADES E EMOÇÕES NAS DEMANDAS POR DIREITOS DE PESSOAS TRANSEXUAIS
}

Lucas Freire $^{1}$

\begin{abstract}
${ }^{1}$ Programa de Pós-graduação em História, Política e Bens Culturais, Centro de Pesquisa e Documentação de História Contemporânea do Brasil, Fundação Getúlio Vargas (PPHPBC/CPDOC/FGV), Rio de Janeiro/RJ, Brasil
\end{abstract}

\section{Introdução}

Este artigo é produto de uma pesquisa etnográfica empreendida entre os meses de fevereiro e agosto de 2014 no Núcleo de Defesa da Diversidade Sexual e Direitos Homoafetivos (Nudiversis) da Defensoria Pública Geral do Estado do Rio de Janeiro (DPGE-RJ). Durante o trabalho de campo, acompanhei as rotinas de trabalho das funcionárias tanto nos atendimentos às/aos usuárias/os do serviço quanto em seus expedientes internos, tendo como foco a demanda por alteração de nome e/ou sexo no registro civil de pessoas transexuais, também chamada de "requalificação civil". No período em que realizei a pesquisa, o Nudiversis contava com uma equipe formada por uma defensora pública, uma assessora, uma técnica-administrativa e duas estagiárias. O fato de todas as profissionais em atuação na instituição serem mulheres é de suma importância, já que ele nos revela uma espécie de "generificação do cuidado" que permeia não só a idealização, mas também o próprio funcionamento do núcleo. ${ }^{1}$ Como será discutido ao longo do texto, sensibilidade, empatia e identificação são elementos presentes no cotidiano do Nudiversis de diferentes maneiras, sendo elencados pela defensora como qualidades indispensáveis para se trabalhar em um local que lida com pessoas cujos percursos de vida são marcados por inúmeros episódios de sofrimento e discriminação. 
O Nudiversis foi oficialmente criado em 2011. Sua concepção foi pensada como parte da campanha de promoção de direitos e inauguração de diferentes serviços de atendimento oferecidos no âmbito do programa "Rio Sem Homofobia", ${ }^{2}$ uma iniciativa do governo do estado do Rio de Janeiro. Em linhas gerais, ele pode ser classificado como um "núcleo especializado de primeiro atendimento". O termo "especializado" indica que a instituição se concentra em lidar com questões e demandas apresentadas por um determinado grupo de sujeitos, no caso, a coletividade denominada "população LGBT" (Aguião 2018), composta por lésbicas, gays, bissexuais, travestis e transexuais. Já a expressão "primeiro atendimento"3 aponta para o fato de que o núcleo atua, ao menos oficialmente, somente em uma etapa préprocessual, ou seja, suas principais funções são realizar o aconselhamento jurídico e, quando necessário, reunir e produzir provas que serão anexadas à petição inicial que será entregue à/ao assistida/o, termo usado para designar as/os usuárias/os dos serviços da Defensoria Pública.

Petição inicial é o nome dado ao documento protocolado em um Tribunal de Justiça para a abertura de um processo judicial. No caso da requalificação civil de pessoas transexuais, a elaboração dessa petição é feita a partir de um modelo previamente estabelecido, após a realização de uma série de procedimentos de acompanhamento executados pelas funcionárias do núcleo. Este modelo possui 36 páginas de texto corrido e é composto por 12 seções: 1. Da gratuidade de justiça; 2. Dos fundamentos fáticos; 3. Considerações sobre a identidade sexual; 4. Considerações sobre o transexualismo; 5. Da possibilidade jurídica dos pedidos; 6. Dos direitos inerentes à personalidade; 7. Do procedimento de jurisdição voluntária; 8. Do panorama normativo; 9. Do panorama doutrinário favorável; 10. Do panorama jurisprudencial; 11. Incursão no Direito Comparado; e 12. Dos pedidos. Quando transformado em uma petição inicial de fato - isto é, quando os poucos espaços em branco do modelo são preenchidos com informações pessoais de um indivíduo - uma série de documentos é anexada ao pedido judicial: fotografias da/o autora/or, certidões de "nada consta" emitidas por diferentes Ofícios de Registro de Distribuição (ORD), Estudo Social, receitas de medicamentos hormonais, laudos de psiquiatras, psicólogos, endocrinologistas, assistentes sociais e quaisquer outros tipos de "papéis" que são considerados úteis para comprovar a veracidade dos relatos e fazer com que a demanda seja julgada procedente.

Meu objetivo neste artigo é apresentar uma análise desse modelo de petição inicial de requalificação civil produzido pelas profissionais do Nudiversis não só em termos do seu contúdo textual, mas também a partir da sua influência no cotidiano do núcleo que pude observar durante o trabalho de campo. Apesar de ter acompanhado o atendimento de mais de 50 usuárias/ 
os e ter tido acesso a um conjunto de cerca de 20 petições iniciais ${ }_{,}{ }^{4}$ privilegio aqui o texto que serve de base para a formulação de pedidos concretos de requalificação civil, uma vez que as mesmas alegações se repetem em todos eles. ${ }^{5}$ Busco abordar quais são os recursos argumentativos acionados para que a requisição de alteração do registro civil de uma pessoa transexual seja autorizada e como estes se fazem a partir de uma imbricação entre compromissos políticos, deveres morais e apelos emocionais.

A leitura desse modelo de petição revela que diversas estratégias são postas em prática pelas funcionárias do Nudiversis na tentativa de fazer com que esta demanda seja atendida. O Princípio da Dignidade da Pessoa Humana - previsto expressamente no art. $1^{\circ}$, III da Constituição Federal como "fundamento" da República Federativa do Brasil - funciona como uma espécie de fio condutor da argumentação desenvolvida e se desdobra em uma série de rogativas e considerações de cunho moral que extrapolam as justificativas baseadas no conjunto de códigos, doutrinas, documentos internacionais de direitos etc. que compreendem o panorama normativo positivado do Direito e suas interpretações consagradas.

Por um lado, ao apelar para certa obrigação moral dos operadores do Direito em promover o bem-estar de todos os cidadãos, em especial aqueles que são considerados como mais "frágeis" ou "vulneráveis", parte da retórica utilizada nesse modelo de petição tenta produzir no indivíduo responsável pelo julgamento da procedência da demanda uma certa empatia pela/o autora/or da ação. Por outro, há também ao longo do texto uma série de denúncias acerca de um tipo de "contaminação moral" por parte dos juízes e promotores que se posicionaram contrários aos pedidos de alteração do registro civil de pessoas transexuais. Para isso, é salientado que não existe norma proibitiva que fundamente tais negativas, sendo estas influenciadas por valores morais, os quais, obedecendo aos pressupostos de um Direito imparcial, técnico, laico e objetivo, não deveriam estar presentes em decisões judiciais. No entanto, ao mesmo tempo em que busca afastar determinadas concepções morais dos processos de decisão, o texto evoca, em diversos pontos e de diferentes formas, o dever moral de promover a dignidade das pessoas transexuais.

Em resumo, discuto aqui como o modelo de petição inicial de requalificação civil produz a vulnerabilidade das pessoas transexuais ao construir evidências dessa condição - que é apresentada como inerente às experiências que envolvem a transexualidade - para que elas tenham sua humanidade reconhecida. Uma vez que tais sujeitos são dintinguidos como humanos, a obrigação dos operadores do Direito de lidar com esta vulnerabilidade, a partir de um dever moral de redução dessa condição, é traduzida na defesa do Princípio da Dignidade da Pessoa Humana. 
Para finalizar esta introdução, destaco que o contexto no qual realizei minha etnografia é bastante diferente do momento atual, já que a luta por direitos de pessoas transexuais obteve ganhos significativos desde então. Um dos avanços mais importantes diz respeito à decisão do Supremo Tribunal Federal (STF) de março de 2018 que permite a alteração do nome e do sexo de pessoas transexuais independentemente da realização da cirurgia de transgenitalização e da apresentação de um laudo pisquiátrico, assim como incentiva que a modificação do registro seja feita nos cartórios sem a necessidade de um processo judicial. Como sublinhado por Coacci (2020), o julgamento da Ação Direta de Inconstitucionalidade (ADI) n. 4275 operou mudanças importantes nas formas pelas quais os saberes são incorporados por agentes e agências do Judiciário e como isso promove uma reconfiguração dos direitos de pessoas transexuais, ou seja, tal decisão faz com que boa parte do expediente para a requalificação civil observada ao longo do meu trabalho de campo já não se aplique mais, em especial a necessidade de protocolar uma petição inicial e, consequentemente, judicializar o caso.

Entretanto, há ainda duas ressalvas que precisam ser feitas sobre este ponto da mudança de cenário e uma imaginável "obsolescência" da pesquisa. A primeira delas implica sublinhar que a atual possibilidade de realizar a modificação do registro civil diretamente nos cartórios origina uma outra sorte de mecanismos e procedimentos burocráticos, os quais permanecem regulando o acesso a direitos por pessoas transexuais, como levantado na dissertação de Pimenta (2020). A segunda diz respeito à amplitude das discussões aqui apresentadas. Como pretendo explicitar ao longo do artigo, as reflexões e as análises feitas a partir desse modelo de petição iluminam de que maneira demandas por direitos encontram-se altamente atravessadas por valores e compromissos morais, bem como por dinâmicas emocionais complexas, especialmente quando ancoradas na figura de uma "vítima" que necessita de reparação e nos ideais dos direitos humanos e dos direitos sexuais.

\section{Vítimas da natureza e da sociedade: a produção da vulnerabilidade das pessoas transexuais}

O modelo de petição inicial de requalificação civil descreve as pessoas transexuais como seres duplamente vitimados: por um lado, tais indivíduos são vistos como uma espécie de vítimas da natureza, pois são acometidos por uma patologia psíquica, o "transexualismo" ou a "disforia de gênero"; 
por outro, são encarados como vítimas da sociedade, uma vez que encontram inúmeras dificuldades em sua vida cotidiana devido aos constantes episódios de discriminação e violência vivenciados por conta de um preconceito largamente difundido. A transcrição abaixo é de um dos parágrafos iniciais do texto desse modelo. A partir deste trecho, é possível observar que o primeiro passo para a construção das pessoas transexuais como "sujeitos de direitos" é a sua produção enquanto "indivíduos em situação de vulnerabilidade".

Considerando que as pessoas que compõem a população de lésbicas, gays, bissexuais, travestis e transexuais (LGBT) encontram especiais dificuldades para exercitar com plenitude ante o sistema de justiça os direitos reconhecidos pelo ordenamento jurídico, enquadram-se no conceito de pessoas em situação de vulnerabilidade da regra $n$. 3 do documento internacional conhecido como "100 Regras de Brasília para o acesso à justiça de pessoas em condiçáo de vulnerabilidade", estando a demandar a atuação do Poder Judiciário e das demais instituições e órgãos integrantes do sistema de Justiça, com o fim de concretizar a efetividade do direito à identidade de gênero, enquanto expressão da dignidade da pessoa humana (Modelo de petição inicial, grifos no original).

Como mencionado anteriormente, uma das seções que compõem o modelo é chamada de "Considerações sobre o transexualismo". Como o próprio título deixa explícito ao mencionar a palavra "transexualismo", tais considerações se baseiam em apropriações das teorias e dos discursos produzidos por autores da Psiquiatria, da Psicologia e da Psicanálise. Tal como pontuado por Leite Jr. (2010), a contemporânea figura da pessoa transexual tem suas origens na ideia de "hermafroditismo psíquico" - ou seja, uma espécie de "inversão sexual" em nível mental - desenvolvida por uma "ciência sexual" que se apoia em e articula estudos das chamadas ciências psi a partir de meados do século XX. Assim, as/os assistidas/os que pleiteiam a alteração do registro civil são incorporadas/os nas instituições - e passarão a figurar nos processos judiciais propriamente ditos - como portadoras/es de uma determinada patologia.

O transexualismo é um fenômeno da sexualidade. Caracteriza-se por uma inversão da identidade psicossocial, que conduz a uma neurose relacional obsessivo-compulsiva, que se manifesta pelo desejo de integral reversão sexual (Modelo de petição inicial, grifos no original).

Seus órgãos sexuais e nome, destoantes de seu psiquismo, são verdadeira fonte de aflição, desespero, repugnância e graves distúrbios psicológicos, que não raras vezes conduzem a tentativas de suicídio e à mutilação da genitália (Modelo de petição inicial, grifos no original) 
Os trechos citados acima elucidam as formas pelas quais diversas teorias sobre a transexualidade são apreendidas. Ao dizer que "o transexualismo é um fenômeno da sexualidade", extingue-se completamente qualquer possibilidade de compreensão da transexualidade como uma experiência que diz respeito somente às percepções dos sujeitos sobre seus próprios corpos e identificações de gênero. Além disso, o termo sexualidade aparece em um registro ambíguo, não sendo possível estabelecer se este faz referência ao exercício de práticas sexuais ou se fala sobre uma determinada concepção ou modo de perceber o sexo enquanto uma categoria que classifica os corpos em masculino ou feminino. ${ }^{6}$

Por se tratar de uma espécie de "distúrbio psicológico", a transexualidade é apresentada nesse documento como fonte de um sofrimento do qual o sujeito não pode fugir e, principalmente, não pode ser considerado culpado. Ao se revestir de um suposto caráter científico, a definição médica do "transexualismo" funciona como um dos elementos que são elencados para que a demanda por requalificação civil destes sujeitos seja vista como justa e legítima, afastando das pessoas transexuais as acusações de desvio moral que geralmente recaem sobre as travestis (Zambrano 2005).

De acordo com Ventura (2010), o diagnóstico do "transexualismo" é do tipo diferencial - ou seja, deve distinguir transexuais, travestis e homossexuais -, uma vez que somente a/o "verdadeira/o transexual" (Bento 2006) pode ter acesso não só às mudanças corporais, mas também ao direito de requalificação civil. Além disso, uma das prerrogativas de tal diagnóstico é constatar a "condição de intenso sofrimento de seu portador" (Ventura 2010). Logo, tal discurso reforça um dos enunciados relacionados à transexualidade que é largamente reproduzido por atores de vários campos: a de que este fenômeno representa um tipo de "erro da natureza" do qual os sujeitos transexuais são vítimas, isto é, a ideia de uma pessoa que "nasceu no corpo errado". Tais teorias também influenciam de modo significativo a construção subjetiva dos indivíduos transexuais. Neste sentido, a ideia de "vítima da natureza" também é reproduzida nos e a partir dos discursos das/os próprias/os assistidas/os do Nudiversis. Durante os atendimentos acompanhados, não raras foram as vezes em que frases como "eu não pedi para nascer assim" e "eu nasci desse jeito" figuraram nas falas dos sujeitos.

Se, por um lado, as pessoas transexuais são consideradas vítimas da natureza, por outro, elas também são vítimas da sociedade. A seção "Dos Fundamentos Fáticos" é a única lacuna que precisa ser preenchida nesse modelo de ação judicial. Como o título sugere, seu propósito é apresentar os "fatos do caso". Tal espaço deve ser completado com episódios concretos das trajetórias dos indivíduos. Em outras palavras, é nessa seção que as 
histórias de vida dos/as assistidos/as são contadas. Entretanto, aquilo que é considerado como um "fato do caso" relevante para a legitimação do direito à modificação do registro civil diz respeito às situações de violência e discriminação vividas pelos sujeitos, o que, em última instância, serve para reforçar a ideia de que as pessoas transexuais são de fato vítimas da sociedade.

Cabe ressaltar que [o Autor] sofreu e sofre diversas discriminações e dificuldades nos locais públicos que frequenta, como bancos, casas de show, cinemas, repartições públicas, salas de espera de hospitais e consultórios médicos e demais locais congêneres, se vendo constantemente exposto e constrangido em razão do prenome [feminino] que carrega em seus documentos. Além disso, encontra dificuldades para ingressar no mercado de trabalho, sendo que, por vezes, é compelido a usar seu nome de registro no ambiente interno às empresas onde trabalha, assim como frequentar o banheiro feminino. Em outras oportunidades, não alcança a efetivação no emprego pela dicotomia entre sua aparência e seus documentos (Modelo de petição inicial).

As narrativas apresentadas como "fundamentos fáticos" de uma ação de requalificação civil elaborada pela equipe do Nudiversis são oriundas das informações registradas no Relatório de Primeiro Atendimento. $\mathrm{Na}$ medida em que nem tudo que é contado pelas/os assistidas/os é considerado interessante para figurar em um processo judicial, a transposição do que é dito para as profissionais do núcleo para um relato contido numa petição inicial - passando pelas anotações da estagiária e a posterior elaboração do relatório - implica um processo contínuo de contração narrativa. A seção do modelo aqui analisada pode ser encarada como a etapa final desse processo de redução, pois, mesmo que existam pequenas brechas, estas são poucas e não permitem a narrativa de nenhum episódio que possa vir a questionar a imagem de vítima da/o autora/or da ação.

A construção da vitimização pela sociedade através da exposição dos "fatos do caso" tem uma inegável relação com o tempo. Ao privilegiar na verdade, quase limitar - os episódios de sofrimento na fabricação das biografias dos sujeitos, tais narrativas fazem com que essas experiências não se limitem ao tempo presente, mas que também tenham marcado o passado e venham a atravessar o futuro caso "nenhuma atitude seja tomada". Assim, esses modos de narrar traz embutida uma espécie de previsão acerca da possibilidade do congelamento dos sujeitos em cenários de dor e angústia. Contudo, para que essa promessa de desgraça não se cumpra, é preciso que outras pessoas se engajem na "mitigação do sofrimento vivido pelas pessoas transexuais cotidiana e ininterruptamente". 
Por fim, ressalto que a centralidade das experiências de sofrimento entre os casos de requalificação civil de pessoas transexuais também pôde ser percebida por meio do acompanhamento das rotinas de trabalho das profissionais do Nudiversis em seus atendimentos e da leitura dos documentos ${ }^{7}$ que constam nas pastas das/os assistidas/os. Os episódios de discriminação, mesmo quando não diretamente relatados, têm sua existência presumida, uma vez que muitos dos parágrafos do modelo de petição inicial que permanecem inalterados salientam este aspecto da vida ordinária dos sujeitos. Entretanto, ao expor tal "presunção do sofrimento", não pretendo revelar nenhum tipo de farsa ou dizer que as pessoas transexuais não sofrem violências e discriminações ao realizarem várias atividades. Busco demonstrar como uma determinada estratégia para o acesso a direitos se fundamenta não apenas em uma legitimidade legal per se, mas também na necessidade de criação de uma figura que é ao mesmo tempo vítima de uma dada configuração social que relega as pessoas transexuais às margens da sociedade e de uma patologia que acomete "sujeitos inocentes".

A fabricação da inocência se dá em dois planos distintos: um moral, por meio do não registro de determinadas falas, como, por exemplo, o caso de uma assistida que durante o primeiro atendimento enfatizou sua vontade de fazer a cirurgia de transgenitalização para poder "dar" como sempre quis, isto é, para exercer a penetração vaginal; e outro mais marcadamente formal - ainda que moral em algum sentido - através da apresentação das certidões de "nada consta" emitidas pelos Ofícios de Registro de Distribuição. ${ }^{8} \mathrm{O}$ sujeito inocente não é só aquele que não cometeu nenhum crime ou delito, mas também alguém que possua um tipo "inocência moral". Em outras palavras, a pessoa transexual idônea é aquela que deseja as intervenções corporais e a requalificação civil apenas para cessar seu próprio sofrimento e viver dignamente, e não para obter qualquer tipo de vantagem.

\section{Em defesa da dignidade: os múltiplos discursos sobre "direitos" que figuram no modelo de petição inicial de requalificação civil}

Uma vez que se tenha construído a figura da pessoa transexual como alguém que está sujeito aos mais diversos sofrimentos, a argumentação apresentada no modelo de petição inicial toma como base a defesa do Princípio da Dignidade da Pessoa Humana. Destaco que o apelo a tal princípio extrapola aquilo que pode ser visto como uma dimensão mais normativa ou positivada constitucionalmente e se desdobra em uma série 
de estratégias discursivas que visam, por um lado, legitimar o pleito pela alteração de nome e sexo através do acionamento da empatia e de um sentimento de pertencimento a uma humanidade comum e, por outro, questionar e deslegitimar as alegações que poderiam ser utilizadas por juízes e/ou promotores para negar ou contestar tais pedidos.

O primeiro argumento utilizado pelas operadoras do Direito no pedido de requalificação civil de uma pessoa transexual é o de que não existe nenhuma proibição legal em relação à alteração do registro civil dos cidadãos. No âmbito formal, é citada a Lei $\mathrm{n}^{\circ}$ 6.015/73, também conhecida como "Lei de Registros Públicos", interpretada de modo a afirmar que o nome pode ser alterado caso exponha a pessoa ao ridículo ou a situações vexatórias. Neste ponto, o texto assume a seguinte forma:

NÃO É OUTRA A SITUAÇÃO DA TRANSEXUAL QUE, A DESPEITO DE UMA APARÊNCIA [FEMININA] E DE COMPORTAMENTO SOCIAL CONSENTÂNEO, TENHA QUE SE APRESENTAR COM PRENOME [MASCULINO] COMPLETAMENTE DESTOANTE DE SUA CONDIÇÃO FÁTICA, SENDO, POR ESTA RAZÃO, ALVO DE CONSTANTE CHACOTA (Modelo de petição inicial, grifos no original).

Além do recurso à Lei de Registros Públicos, a leitura do modelo de petição inicial revela que há uma combinação entre distintos discursos sobre "direitos" como formas de legitimar a demanda pela requalificação civil de pessoas transexuais: o direito à saúde, o direito à autodeterminação sexual e o direito à dignidade, dispostos nesse modelo de modo sobreposto e articulado. Grosso modo, o direito à saúde faz referência ao dever do Estado de assegurar que os cidadãos tenham acesso às melhores condições de saúde disponíveis através da prestação de serviços públicos; já o direito à autodeterminação sexual incorpora um discurso sobre a liberdade ao ser descrito como um dos direitos inerentes à personalidade e diz respeito à proteção da intimidade, da vida privada, da honra e da imagem; o direito à dignidade, por sua vez, fala sobre a efetivação de condições fundamentais para o exercício da cidadania.

O surgimento de um discurso sobre a defesa dos ditos "direitos sexuais" se deu simultaneamente ao desenvolvimento de um pleito pela aquisição de "direitos reprodutivos", ainda que estes abarquem demandas profundamente diferentes (Vianna 2012). No cenário político contemporâneo, uma retórica sobre o exercício de direitos sexuais tem sido apropriada de um modo específico por atores ligados aos movimentos sociais LGBT, incorporando em seu escopo questões que a princípio nada têm a ver com o exercício da sexualidade, como, por exemplo, temas ligados aos direitos previdenciários 
(Carrara 2010). No contexto do Nudiversis, para as demandas mais singulares de travestis e pessoas transexuais, o discurso sobre direitos sexuais se traduz na luta por determinadas "liberdades fundamentais", como, por exemplo, a autodeterminação da identidade sexual/de gênero.

Outro direito que ganha extrema relevância no caso é o direito ao reconhecimento perante a lei. Considerando que a orientação sexual e a identidade de gênero constituem parte essencial da personalidade e um dos aspectos mais básicos de sua autodeterminação e dignidade, deve o Estado "tomar todas as medidas legislativas, administrativas e de outros tipos que sejam necessárias para que existam procedimentos pelos quais todos os documentos de identidade emitidos pelo Estado que indiquem o sexo/gênero da pessoa - incluindo certificados de nascimento, passaportes, registros eleitorais e outros documentos - reflitam a profunda identidade de gênero autodefinida por cada pessoa", de maneira a salvaguardar os direitos dessas minorias (Modelo de petição inicial, grifos no original).

Apesar de serem relativamente difundidos entre militantes e atores dos movimentos sociais, os direitos sexuais não parecem se constituir como a via mais importante ou legítima para defender o direito à requalificação civil de pessoas transexuais atendidas no núcleo. O modelo de petição inicial traz somente uma única referência a essa expressão. Além disso, os direitos sexuais aparecem colados aos direitos reprodutivos e, por conta dessa articulação, subordinados ao "direito à saúde".

A mobilização de um dado conceito de saúde e de um subsequente direito ao usufruto de melhores condições físicas e mentais era possível nesse modelo porque a transexualidade figurava como uma "disforia de gênero" na edição contemporânea do Manual Diagnóstico e Estatístico de Transtornos Mentais ${ }^{9}$ (DSM) e como "transexualismo" na 10a edição da Classificação Internacional de Doenças ${ }^{10}$ (CID). Desse modo, ao definir a transexualidade como uma espécie de patologia, transformando-a, assim, em uma "questão de saúde pública", os médicos retiraram - em certa medida - das mãos do Legislativo a hegemonia da competência para regular os "direitos" das pessoas transexuais.

Apesar da patologização da transexualidade encapsular os indivíduos no dispositivo da transexualidade (Bento 2006), transformando-os em "verdadeiros transexuais", o fato de existir algo que seja considerado como uma "terapia de mudança de sexo" faz com que o Estado seja obrigado a oferecer serviços públicos de saúde voltados para o atendimento de pessoas transexuais. Contudo, tal categorização produz corpos inteligíveis que, ao serem reconhecidos no interior do dispositivo da transexualidade, 
encontram-se incluídos em uma economia jurídico-moral que regula o "acesso aos direitos". Assim, a despeito de excluir as/os "outras/os transexuais", estes serviços - muitos deles ligados ao Sistema Único de Saúde (SUS) - representam um dos únicos caminhos para que aqueles que possuem baixo poder aquisitivo tenham suas demandas por modificações corporais atendidas, tendo em vista o alto custo tanto das aplicações hormonais quanto dos diversos tipos de procedimentos cirúrgicos na rede privada de serviços de saúde (Almeida \& Murta 2013). Ademais, caso não fossem consideradas "terapêuticas", as cirurgias que implicam a intervenção nos e/ou retirada de órgãos poderiam ser legalmente enquadradas como "crime de lesão corporal", pois seriam vistas como mutilação e/ou amputação de partes do corpo consideradas saudáveis. Isto acarretaria não somente a criminalização, como também a cassação do Registro Profissional de Médico do cirurgião que realizasse tais procedimentos em alguém.

Na pesquisa empreendida por Miriam Ventura (2010), o discurso sobre o direito à saúde aparece como a principal forma pela qual a demanda pela modificação do registro civil de pessoas transexuais encontrou respaldo no Judiciário. Entretanto, a autora afirma que a mudança retórica pela qual o fenômeno da transexualidade passou, no âmbito jurídico, a partir dos anos 1990, saindo do Direito Penal que condenava a cirurgia de transgenitalização para integrar o debate sobre um "direito humano à saúde" não necessariamente promoveu a autonomia dos sujeitos transexuais. No âmbito do Nudiversis, o direito à saúde é citado em alguns pontos do modelo de petição, sendo descrito como fundamental para o desenvolvimento do sujeito. Contudo, do mesmo modo que os direitos sexuais, o direito à saúde não aparece isolado, mas sim conectado ao dever do Estado de promover a cidadania e de se comprometer com a defesa do Princípio da Dignidade da Pessoa Humana, como podemos verificar no exemplo a seguir.

Assim é que o direito à vida, o direito à integridade psicofísica e o direito à saúde constituem o trinômio que informa o livre desenvolvimento da personalidade e a salvaguarda da dignidade do ser humano, traduzindo-se, finalmente, no exercício da cidadania (Modelo de petição inicial, grifos no original).

A superação das barreiras e das limitações impostas por um discurso sobre direito à saúde só pode ser alcançada na medida em que a concepção de saúde é alargada e passa a designar não apenas a ausência de doenças, mas também o bem-estar do corpo e da mente. A ideia de bem-estar defendida no modelo de petição inicial encontra-se articulada à noção de dignidade, a qual, por sua vez, reflete o pleno exercício da cidadania. 
A saúde, muito embora venha assegurada fora do rol exemplificativo do art. $5^{\circ}$, da Lei Magna, é garantia de extrema importância, posto que sua pedra angular é o próprio princípio da dignidade da pessoa humana, o qual não apenas consiste em um dos fundamentos do Estado Democrático de Direito, como consagra expressamente o art. $1^{\circ}$, mas também caracteriza o cerne axiológico de todo o ordenamento jurídico (Modelo de petição inicial, grifos no original).

[...] uma vez negado o presente pleito, condenar-se-á a Autora a um ininterrupto e profundo sofrimento - penalizando-a pela ineficiência do Estado em prover os serviços de saúde essenciais, uma vez que o Transtorno de Identidade de Gênero inscreve-se no CID-10 (através do Código F64) e o Ministério da Saúde oferece, pelo menos no plano do dever-ser, o tratamento adequado à "patologia" (Modelo de petição inicial, grifos no original).

Em suma, apesar de ser mencionado em vários documentos internacionais de direitos humanos que tratam dos direitos de pessoas transexuais, o "direito à saúde" não é protagonista da argumentação desenvolvida pelas profissionais do Nudiversis. O discurso sobre o caráter terapêutico das alterações de nome e sexo no registro civil - conforme apontado nas pesquisas feitas por Zambrano (2005), Ventura (2010) e Teixeira (2013) - fica ofuscado pelo dever moral de minimização do sofrimento e promoção da dignidade e da cidadania.

$\mathrm{O}$ direito à dignidade aparece nesse modelo de petição inicial como a principal forma de argumentação para que o pedido de alteração do registro civil de pessoas transexuais seja atendido. Ainda que as análises feitas aqui não se orientem por um viés quantitativo, chama a atenção o fato de a palavra "dignidade" aparecer 34 vezes ao longo do texto. Levando em consideração que esse documento possui 36 páginas, há uma média de quase uma menção por página, o que indica certa centralidade da ideia de dignidade.

As alegações apresentadas nessa peça processual extrapolam, de certa forma, a dimensão normativa positivada ao construir uma série de apelos emocionais e deveres morais tendo como fundamento o Princípio da Dignidade da Pessoa Humana. Em outras palavras, no contexto dos processos judiciais envolvendo transexuais, tal discurso não se limita à defesa de um "princípio jurídico", mas também fala sobre um modo de fazer política que pode ser eficaz em um dado quadro da "economia moral contemporânea" (Fassin 2012).

A Constituição de 1988, no Título I, ao tratar dos princípios fundamentais que norteiam a República Federativa do Brasil, destaca, no art. $1^{\circ}$, inc. II e III, a valorização da cidadania e da dignidade da pessoa humana, elegendo, desta 
forma, valores humanitaristas como alguns dos princípios objetivos do Estado e da Sociedade. Assim, é que a obrigação de garantir o bem-estar do cidadão, zelar por sua dignidade e pelo livre desenvolvimento de sua personalidade encontram amparo constitucional (Modelo de petição inicial, grifos no original).

Como aparece explicitado nessa citação, a Constituição Federal de 1988 - também conhecida como "Constituição Cidadã" - é representativa da incorporação de "valores humanitaristas" nas normativas legais brasileiras, inaugurando novas formas de imbricação entre moral e política. A defesa do Princípio da Dignidade da Pessoa Humana se insere em um cenário ético e político em que a pressão moral de ser compassivo é acionada estrategicamente para que o pedido de alteração do registro civil de pessoas transexuais seja atendido pelos membros do Judiciário. As considerações morais contidas no texto falam basicamente do dever dos operadores do Direito, enquanto pertencentes a uma mesma "humanidade" que as pessoas transexuais, de se solidarizarem com as situações de discriminação vivenciadas constantemente pelas/os assistidas/os e, consequentemente, de se engajarem em medidas concretas que tenham por objetivo aplacar o sofrimento destes sujeitos. Assim, tais colocações fabricam a imbricação entre política, moralidade e apelos sentimentais, a qual fica clara em diversos pontos do modelo de petição inicial de requalificação civil formulado pelas operadoras do Direito que atuam no Nudiversis.

\section{"Decisões contaminadas": acusações morais e a estratégia de deslegitimação}

Existe um aspecto no modelo de petição inicial que, em um primeiro momento, pode parecer paradoxal. Se, por um lado, há uma série de apelos morais e emocionais utilizados para que se reconheça como "justa" a demanda pela alteração de nome e/ou sexo no registro civil de pessoas transexuais, por outro, a possibilidade de negação de tal pleito é inscrita a partir de uma série de considerações e acusações mais ou menos explícitas de uma espécie de "contaminação moral" dos responsáveis pelo julgamento.

Inicialmente, impende evidenciar que, no Direito Pátrio, não há norma proibitiva com relação ao tema. Óbices derivam, sobretudo, de considerações de cunho moral, religioso e social que partem, evidentemente, de suposições preconceituosas e de um total alheamento a questões que afligem tão dramaticamente os seres humanos portadores de deficiências ou características que os tornem diferentes dos demais (Modelo de petição inicial, grifos no original). 
A Lei de Registros Públicos, diploma específico, é omissa, sendo certo que as decisões até agora prolatadas trazem como fundamento considerações de ordem moral ou religiosa, no sentido de desconsiderar os avanços no campo da pesquisa científica. Como negar ao transexual uma vida digna?! Uma identidade que realmente o espelhe?! Como livrá-lo da execração preconceituosa?! (Modelo de petição inicial).

Para tentar compreender aquilo que estou chamando aqui dos alertas sobre o perigo da contaminação moral de alguns atores ligados ao Judiciário, aproprio-me das proposições de Luc Boltasnki acerca da formulação de denúncias e formas de exposição dos casos, bem como nas suas ideias sobre o tom urgente presente nas descrições das situações de sofredores que marca o que ele chama das políticas da piedade. Se para Boltanski (1999) o contágio emocional é um traço fundamental para o estabelecimento da relação entre aquele que sente necessidade de ajudar e aquele que é descrito como precisando de ajuda, acredito que é possível observar como essa ideia se desdobra na argumentação desenvolvida no modelo de petição inicial de requalificação civil aqui analisado. Como abordarei na próxima seção do artigo, o contágio emocional dos agentes do Judiciário é um objetivo do uso de uma retórica da compaixão. Contudo, esse contágio emocional só é encarado pelas profissionais do núcleo de maneira positiva e bem-sucedida quando alinhado ao posicionamento de defesa de direitos e promoção da dignidade humana de pessoas transexuais. Nas situações em que a demanda é julgada improcedente, o contágio emocional converte-se em uma espécie de contaminação moral que mancha as decisões judiciais e que precisa ser denunciada.

Para Boltanski (1990), um dos fatores que podem tornar uma denúncia eficaz é a correta disposição de três elementos: as vítimas, sujeitos que sofrem algum infortúnio; os espectadores engajados, pessoas moralmente comprometidas com a denúncia de uma determinada mazela ou violação; e os perpetradores, aqueles que são acusados de causar o sofrimento das vítimas. Nesse sentido, as críticas feitas à negação dos pedidos de alteração do registro civil de pessoas transexuais assumem a forma de uma "denúncia" na medida em que os sujeitos envolvidos nos casos são posicionados da seguinte maneira: transexuais como vítimas; defensores públicos como espectadores engajados; e juízes que negam os pedidos e promotores que recorrem de decisões de procedência, senão como perpetradores, ao menos como coniventes com os causadores do sofrimento que aflige as pessoas transexuais. Esta disposição dos elementos fica evidente nos seguintes trechos do modelo: 
A partir do momento em que uma ciência como o Direito, a qual tem um poder de influência imenso nos comportamentos humanos, se abstém de tutelar os interesses de indivíduos invisíveis socialmente, os operadores do Direito tornamse não somente omissos nos processos cotidianos de violação dos direitos da personalidade das quais os transexuais e travestis são vítimas, mas passam a ser agentes violadores dos direitos de tais grupos populacionais (Modelo de petição inicial, grifos do autor).

Para os que consideram um caso, como o dos autos, uma violação às regras sociais, pergunta-se: a Requerente deveria ser mantida como pária social, recebendo uma punição, não escrita na lei, ditada aparentemente pela moral e pelos bons costumes, mas substancialmente pelo preconceito e pelo temor de servir de estímulo a tais transformações? (Modelo de petição inicial).

O último trecho transcrito vem logo após a citação de uma sentença na qual um juiz negou o pedido de requalificação civil de uma mulher transexual. Nota-se que, além da contaminação moral, tais discursos acusam aqueles que negam tais pedidos de agentes violadores de direitos - reforçando o caráter de denúncia de tal modo de argumentação - ora de forma implícita, como nas perguntas retóricas, ora de forma direta, como na primeira citação acima.

A partir deste ponto, fica evidente como os modos de argumentação contidos no modelo de petição inicial operam um embate entre duas concepções de moralidade distintas, as quais podem ser denominadas "tradicional" e "humanitária". As considerações presentes nesse modelo funcionam como formas de expor o absurdo da negação do pedido de alteração do registro do civil e localizar nesses magistrados e promotores a responsabilidade pela reprodução do mal e do tormento que afligem as pessoas transexuais (Gluckman 1972). Nesse sentido, as alegações buscam afastar aquilo que poderia ser considerado como uma espécie de moralidade tradicional, ligada não só a concepções essencializadas e biologizantes do sexo, mas também a uma visão conservadora dos papéis e dos lugares sociais ocupados por homens e mulheres. Para a equipe do núcleo, o "moralismo" que contamina as decisões é de um tipo que encara a transexualidade como uma transgressão moral que, se não pode ser judicialmente condenada, ao menos não transforma as pessoas transexuais em "merecedoras de direitos".

Ao mesmo tempo, esses enunciados tentam incutir nos agentes do Judicário uma ideia de que são eles os responsáveis por amenizar o sofrimento e proporcionar às pessoas transexuais condições para que elas possam atingir uma situação de bem-estar e de pleno exercício da cidadania. Assim, o texto visa introduzir uma outra ordem moral que deve embasar as 
decisões judiciais nessa matéria. Essa outra moralidade deve ser baseada no compromisso com a defesa dos direitos humanos de sujeitos socialmente vulneráveis que marca a ascensão da "razão humanitária" (Fassin 2012) no plano político, isto é, uma moralidade humanitária.

Cabe ainda ressaltar que esse embate entre moralidades reflete as tensões originadas pelo reposicionamento da transexualidade tanto nos planos éticoprofissionais de médicos e operadores do Direito quanto em um plano moral mais amplo. A mudança de estatuto da cirurgia de transgenitalização - que deixa de ser uma mutilação e passa a ser considerada como terapêutica - e a consolidação das teorias e dos saberes das ciências psi acarretam a modificação das concepções morais que cercam a transexualidade, que não é mais vista como um "desvio moral", mas sim como uma patologia que acomete alguns "sujeitos inocentes". Essa visão patologizadora faz com que a argumentação em favor do direito à requalificação civil passe a ter como pedra angular a luta pelo "direito à saúde" e a defesa do "Princípio da Dignidade da Pessoa Humana", apelando sempre para a obrigação dos operadores do direito de amenizar o sofrimento de "indivíduos doentes" e oferecer a estes sujeitos condições para uma "vida digna".

\section{Sofro, logo tenho direitos: a retórica da compaixão e uma "política das vítimas"}

Para compreender o modo pelo qual a economia jurídico-moral que regula o acesso aos direitos pode ser operada através do acionamento do Princípio da Dignidade da Pessoa Humana e como isso se torna um discurso politicamente eficaz em um determinado contexto, é preciso entender de que forma se produziram as conexões entre empatia, compaixão, valores morais, compromissos políticos, governo humanitário e direitos humanos; ou ainda, como o subtítulo do texto sugere, como emoções e moralidades imiscuem-se nas demandas por direitos de pessoas transexuais. Assim, nesta parte do artigo, busco costurar as seções anteriores por meio da construção de um raciocínio sobre a produção de uma forma de reivindicação de direitos que tem como base a figura de um sujeito vulnerável, o qual é, consequentemente, uma vítima sofredora que necessita de ajuda para aliviar suas dores e mazelas.

Ao ser exposto ao sofrimento e às evidências da condição de vulnerabilidade das pessoas transexuais, o leitor desses relatos é, de certo modo, envolvido na situação. A narrativa produz um efeito de cumplicidade naquele que escuta, lê, ou tem acesso de algum modo aos infortúnios 
vividos pelo outro (Gregori 1993). É no contexto de cumplicidade - em que se omitir é visto como uma forma de compactuar com os agressores das vítimas - que o apelo ao Princípio da Dignidade da Pessoa Humana pode se tornar eventualmente eficaz, uma vez que a condição de cúmplice só pode ser quebrada se o sujeito atuar ativamente para mitigar as dores do outro de alguma forma, tornando-se assim aquilo que Boltanski (1999) chama de "benfeitor". A figura do benfeitor é um elemento essencial para a concretização de um modo de ação política que o autor denomina de tópica do sentimento, marcado pela bondade dos que ajudam e pela gratidão dos que são ajudados. São os discursos acerca dessa necessidade de atuação por parte de "atores engajados" que chamo de retórica da compaixão.

A ideia de retórica da compaixão aqui discutida tem como inspiração as noções de retórica emocional (emotion talk) de White (1990) e dos "usos táticos das paixões" de Bailey (1983). White destaca a dimensão discursiva das emoções e afirma que "a expressão de uma emoção se torna um pronunciamento ou uma reclamação (geralmente implícita) sobre o modo como as coisas são ou, mais significativamente, como elas deveriam ser" (White 1990:49, tradução minha). O autor empreende um esforço no sentido de evidenciar como uma fala sobre os sentimentos é capaz de veicular uma espécie de linguagem moral, destacando duas ideias fundamentais: 1. a capacidade de movimentos retóricos transformarem realidades socioemocionais; e 2 . o potencial do discurso emocional de falar um dado idioma moral compartilhado. Bailey, por sua vez, busca demonstrar como estratégias retóricas fazem com que as emoções funcionem como "dispositivos de persuasão" capazes de alterar o curso de certas ações por meio de efeitos morais.

De acordo com Fassin (2012), os sentimentos morais se tornaram uma força essencial nas políticas contemporâneas. Tais sentimentos conectam afetos e valores morais na produção daquilo que ele nomeia de política da compaixão, característica do governo humanitário. O argumento exposto pelo autor afirma que o desenvolvimento de uma forma de gestão baseada em valores humanitários está associado a uma nova economia moral que rege os modos de fazer política, cujo surgimento tem a ver com as mudanças nos sentidos atribuídos à violência e à injustiça, alterando, assim, o modo pelo qual determinadas situações são investidas de significados. Ao analisar o contexto etnográfico dos pedidos de legalização de residência na França de imigrantes enfermos, Fassin propõe o conceito de protocolo da compaixão, em uma analogia ao jargão médico que postula protocolos clínicos e terapêuticos. 
De modo resumido, os apelos contidos nos formulários preenchidos e nas narrativas apresentadas se dão através da empatia e do reconhecimento de um sentimento de humanidade comum, o que funcionaria como um modo de garantir o direito de permanência dos imigrantes.

A localização do papel da empatia é fundamental para a compreensão do modo pelo qual uma espécie de política centrada em um discurso sobre a compaixão adquiriu protagonismo no cenário político atual. Compreendo como ponto principal da defesa do Princípio da Dignidade da Pessoa Humana presente no modelo de petição inicial de requalificação civil de pessoas transexuais a tentativa do estabelecimento da empatia, ou seja, de uma capacidade de se reconhecer no outro ou, ao menos, de perceber o outro como um igual e possivelmente se identificar com seu sofrimento. É a partir do estabelecimento deste terreno comum por meio da empatia que é possível pensar na possibilidade de eficácia da retórica da compaixão para o reconhecimento de determinados grupos ou populações como "sujeitos de direitos".

Do mesmo modo que os pedidos apresentados pelas pessoas transexuais são julgados por um juiz ou desembargador, os formulários que pleiteiam o direito de residência discutidos por Fassin (2012) são avaliados por médicos peritos. Em ambos os casos, instauram-se figuras que representam um poder-saber e que têm autoridade para determinar se tais demandas são ou não legítimas de serem atendidas. Assim, a retórica da compaixão tem por função convencer essas "autoridades" acerca da legitimidade e da procedência jurídica e moral do pedido de alteração do registro civil de uma pessoa transexual. Cumpre então destacar que a emergência da compaixão é sempre perpassada por relações desiguais de poder entre aqueles que sofrem e precisam de ajuda e aqueles que se comovem e podem ajudar (Garber 2004). Neste sentido, o apelo empático contido no modelo de petição inicial reflete não apenas as relações de poder marcadamente assimétricas entre aqueles que são julgados e aqueles que julgam, mas também os distintos princípios morais que regem a vida em sociedade.

No caso das pessoas transexuais, o acesso à "terapia de mudança de sexo" e, consequentemente, a todos os direitos contidos em tal processo - mudanças corporais, alterações de prenome e sexo no registro civil etc. - só é concedido àquelas que são classificadas como "verdadeiramente transexuais", ou seja, os indivíduos que possuem documentos que comprovem tal condição, documentos estes que só são concedidos após uma série de avaliações, exames, entrevistas etc. Lembrando que a "disforia de gênero" constitui, no discurso médico-psiquiátrico, um tipo de transtorno mental caracterizado por uma série de sofrimentos nos planos psíquico e 
social, logo, a promoção de direitos está intimamente ligada à percepção de condição de vulnerabilidade e vitimização das pessoas transexuais, cuja produção foi demonstrada na primeira parte do texto.

O reconhecimento de determinados sujeitos como vítimas implica uma série de dilemas morais quanto às ações dos atores sociais em um contexto como esse. Todos os elementos até agora discutidos - isto é, vulnerabilidade, vitimização, empatia, compaixão e dever moral de atuação dos operadores do Direito - encontram-se condensados na seguinte passagem do modelo de petição inicial:

Contudo, é notório que os transexuais há muito vêm sendo vítimas de discriminação e represálias. Ora, um direito à intimidade, protegido constitucionalmente, abrange, necessariamente, a tutela do interesse das minorias que, por serem minorias, enfrentam maiores dificuldades de exercer com plenitude seus direitos, a demandar atuação pronta e sensível do Poder Judiciário, que, nesse aspecto, atua como guardião da democracia e do Estado de Direito (Modelo de petição inicial, grifos do autor).

Apesar de trabalhar no registro do sofrimento e da vitimização associados às experiências de violência física atendidas em um contexto hospitalar, os escritos de Sarti (2009) podem ser apropriados para pensar o encadeamento do acesso aos direitos à condição de reconhecimento enquanto vítima de uma violência, de um infortúnio, de uma doença ou qualquer outra forma de sofrimento. A autora explora o nexo entre uma categoria diagnóstica - o stress pós-traumático - e uma categoria social - a vítima. A relação entre vítima e trauma, trabalhada também por Fassin (2012) e Fassin e Rechtman (2009), coloca os psiquiatras em uma posição de indispensabilidade, pois são eles que têm a legitimidade necessária para atestar, com eficácia, a condição de vítima de alguém. No marco da expansão do discurso do direito à saúde e ao bem-estar, "a vítima ganha reconhecimento e se afirma por meio dos seus 'direitos'" (Sarti 2009:100). Em outro artigo, Sarti (2011) elabora mais detidamente a politização da figura da vítima e sugere que a vitimização seja encarada como um processo de reconhecimento social do sofrimento e de legitimação moral das demandas por direitos de certos grupos identitários. No caso do modelo de petição inicial de requalificação civil aqui analisado, proponho que a vitimização produzida pelos relatos de violência e discriminação contidos no tópico "dos fundamentos fáticos" da ação tem por objetivo legitimar a necessidade de alteração do registro civil das pessoas transexuais não apenas em um plano jurídico-formal, mas também em um plano ético-moral. 
Uma observação que Sarti (2009) faz é que a produção da vítima tende a essencializar sujeitos e a cristalizar identidades, dando visibilidade a determinados indivíduos e/ou grupos e invisibilizando outros. Esta homogeneização dos sujeitos e das experiências também foi descrita por Fonseca e Cardarello (1999) como um dos efeitos da produção de discursos sobre determinados "sujeitos de direitos". O processo de definição da/o "verdadeira/o transexual" reproduz tal prática ao visibilizar determinadas experiências e legitimar as demandas de algumas pessoas - aqueles que adquirem o laudo da "disforia de gênero" e outros documentos comprobatórios -, ao mesmo tempo em que nega o direito às transformações solicitadas por aquelas que não se encaixam no modelo previsto, apagando outras formas de experimentar a transgeneridade como, por exemplo, a travestilidade.

Outro ponto que merece ser ressaltado é que, segundo Sarti (2011), no campo da saúde, a circunscrição da vítima implica também a circunscrição do sofrimento e do cuidado que lhe corresponde. Estendo as proposições da autora para a esfera judiciária na medida em que verifico que existe no cenário da Defensoria Pública um modelo de procedimentos de assistência - ou até mesmo um protocolo da compaixão (Fassin 2012) - que em parte se assemelha ao contexto descrito pela autora. Tal reflexão dialoga com a produção de Bento (2006) sobre o dispositivo da transexualidade, principalmente se levarmos em consideração que tal dispositivo delimita os sujeitos não só no interior de uma patologia específica, como também oferece como única forma de "tratamento", a chamada "terapia de mudança de sexo" - a qual compreende um conjunto de procedimentos que só pode ser adotado em sua totalidade. Desse modo, a autonomia - um dos valores tidos como fundamentais para a efetivação dos direitos humanos - da pessoa transexual ficaria suspostamente limitada à procura dos serviços, sejam os programas transexualizadores, seja a Defensoria Pública.

Em suma, a partir dos fragmentos do modelo de petição inicial trazidos ao longo do texto, fica claro como diferentes compromissos políticos, valores morais e rogativas emocionas se combinam para legitimar o direito à requalificação civil de pessoas transexuais e a procedência dessa demanda perante juízes, promotores e desembargadores. Os apelos emocionais são construídos nesse modelo por meio de um discurso centrado no direito à dignidade e, assim, aciona-se a empatia, que figurará como base da retórica da compaixão e instituirá um tipo de dever moral e responsabilidade pela amenização do sofrimento vivenciado pelas pessoas transexuais. 


\section{Considerações finais}

Ao longo do texto, busquei demonstrar como as alegações contidas no modelo de petição inicial de requalificação civil seguem uma determinada linha: inicialmente, produz-se uma condição de vulnerabilidade das pessoas transexuais, que são descritas como vítimas de uma patologia e de experiências constantes de discriminação e violência, gerando, assim, um incessante sofrimento; o sofrimento dos sujeitos deve ser amenizado pela efetivação daquilo que é concebido enquanto "seus direitos", os quais, supostamente, garantiriam o pleno exercício da cidadania e a dignidade, cuja obrigação de promover é de responsabilidade do Estado e, consequentemente, dos operadores do Direito. Sobre isso, é preciso destacar que essas questões e ideias encontram eco nas recentes pesquisas empreendidas por Alexandre (2015), Lima (2015), Rego (2015), Pinheiro (2016), Borba (2016), Oliveira (2017), Besen (2018), dentre outros, as quais vêm destacando a articulação entre moralidades, saberes e emoções na defesa dos direitos e na promoção da cidadania, bem como na produção de categorias que conformam subjetividades e atribuem sentidos às experiências vividas por pessoas transexuais. Para encerrar este artigo, gostaria de traçar algumas reflexões e questionamentos acerca daquilo que poderia ser considerado a face perversa do maior chavão do "direito à igualdade" contido no artigo $5^{\circ}$ da Constituição de 1988: "todos são iguais perante a lei, sem distinção de qualquer natureza", já que a padronização atravessa o cotidiano do Nudiversis de diferentes formas.

A uniformização de procedimentos de assistência, a homogeneização das experiências de sofrimento e o apagamento das singularidades e das subjetividades puderam ser percebidos na medida em que pude acompanhar o quanto esses processos de auxílio jurídico e de elaboração de petições iniciais concretas estão ancorados em um modelo previamente definido. Isto se torna ainda mais evidente quando observamos que as diferenças entre as petições iniciais efetivamente entregues às/aos assistidas/os limitam-se aos seus nomes, informações pessoais e a alguns relatos mais marcantes sobre suas trajetórias, os quais são apresentados como "fundamentos fáticos" no processo.

Esta questão aparece de variadas maneiras nas pesquisas que abordam o fenômeno da transexualidade. De acordo com Bento (2006), a generalização da experiência transexual oculta as estratégias de poder e controle que produzem um suposto sujeito universal. O dispositivo da transexualidade, ao postular a existência da/o "verdadeira/o transexual", ignora uma multiplicidade de transexualidades existentes. Já Ventura (2010) 
discute como a regulamentação do processo transexualizador pelo Conselho Federal de Medicina (CFM) reproduz uma lógica de dominação que retira a autonomia das pessoas transexuais no que diz respeito às intervenções corporais, autonomia esta que fica restrita à busca pelo "tratamento". No âmbito jurídico, Zambrano (2005) verifica que somente os sujeitos que realizaram as modificações corporais dentro dos critérios estabelecidos pelo CFM podiam requerer a alteração do registro civil, negando este direito aos indivíduos que não seguiram por esse caminho, como, por exemplo, as pessoas que fizeram a cirurgia de transgenitalização em outro país. Teixeira (2013), por sua vez, demonstra de que forma o cumprimento dos protocolos estabelecidos pelo programa de transgenitalização silencia as construções subjetivas da experiência transexual.

Poderia então terminar o artigo fazendo uma espécie de denúncia sobre como o modelo de petição inicial de requalificação civil aprisiona as pessoas transexuais em uma figura essencialmente vitimada e como uma retórica da compaixão poderia ser operativa de um trabalho micropolítico de reiteração de hierarquias e relações desiguais de poder (Rezende \& Coelho 2010). Ou ainda, afirmar que este movimento faz parte de uma pressão homogeneizante do Estado (Williams 1989) que, para produzir espaços e instâncias administrativas eficazes, opera o apagamento de uma série de marcadores sociais da diferença, tais como raça, etnia, classe, sexo, orientação sexual etc.

Contudo, baseando-me nas análises e nas discussões até aqui apresentadas, proponho que a homogeneização acarretada pelos procedimentos de assistência que envolvem a requalificação civil de pessoas transexuais seja vista não como um desdobramento inevitável da micropolítica da compaixão, mas sim como uma forma particular de agenciamento - não somente das pessoas transexuais, mas também daqueles que se engajam na luta pela efetivação dos seus direitos - que permite que tais indivíduos possam se constituir enquanto "sujeitos de direitos". Para pensar sobre isso, aproprio-me de modo relativamente livre das reflexões expostas por Mahmood (2005). Ao criticar o modo como diversos autores das Ciências Sociais conceberam uma noção de agência estritamente ligada a uma ideia de resistência e insubmissão, a autora afirma que "a capacidade de agência não está vinculada somente aos atos que resistem às normas, mas também nas múltiplas formas pelas quais as normas são habitadas" (Mahmood 2005:15, grifos no original).

Assim, ao trazer para a arena pública narrativas sobre sofrimentos e violências de diversas ordens, não acredito que as profissionais do Nudiversis estejam simplesmente reproduzindo e reforçando uma posição de 
vulnerabilidade e vitimização. Também não concordo com uma interpretação que colocaria as pessoas transexuais como meras espectadoras que acatam passivamente uma posição subalterna de vítima. Pelo contrário, considero que, ao exporem não só os relatos de dores e suplícios que marcam as vidas de pessoas transexuais, mas também um conjunto de documentos que certificam que esses sujeitos se enquadram nos critérios diagnósticos da "disforia de gênero", funcionárias e assistidas/os utilizam estrategicamente uma forma de fazer política para que o acesso aos direitos pleiteados seja moral e juridicamente legitimado.

Em outras palavras, enfatizo aqui não a violência da estandardização - que é real e constantemente denunciada por ativistas transexuais -, mas sim os ganhos que essas pessoas podem ter caso elas habitem as normas, para utlizar a expressão cunhada por Mahmood (2005). Por fim, reitero que, ao problematizar tal homogeneização, não pretendo afirmar que as pessoas transexuais não possam compartilhar de episódios comuns de discriminação ou mesmo dizer que estas histórias são ficcionais, mas sim demonstrar como um modo de fazer política baseado na retórica da compaixão encontra espaço nos embates por direitos no cenário ético e moral contemporâneo.

Recebido em 05 de fevereiro de 2020

Aprovado em 10 de junho de 2020

Lucas Freire atualmente realiza estágio pós-doutoral no Programa de PósGraduação em História, Política e Bens Culturais do Centro de Pesquisa e Documentação de História Contemporânea do Brasil da Fundação Getúlio Vargas (PPHPBC/CPDOC/FGV). É mestre e doutor em Antropologia Social pelo Programa de Pós-Graduação em Antropologia Social do Museu Nacional da Universidade Federal do Rio de Janeiro (PPGAS/MN/UFRJ), onde também atua como pesquisador do Núcleo de Estudos em Corpos, Gênero e Sexualidade (NuSEX). Seus principais interesses de pesquisa são gênero, sexualidade, saúde, litígios judiciais, direitos, práticas estatais e administração pública.

https://orcid.org/0000-0002-9629-6840

E-mail: lucas.mfreire@hotmail.com 


\section{Notas}

1 Ao longo do tempo em que permaneci frequentando o Nudiversis, pude acompanhar a equipe que estava trabalhando lá desde a sua inauguração, exceto as estagiárias, que geralmente permaneciam no núcleo por cerca de um ano (sendo dois anos o período máximo que alguém pode ser contratado como estagiário da DPGERJ). Nos anos seguintes, após o fim do trabalho de campo, o Nudiversis passou por algumas transformações, tais como a mudança de endereço; a inclusão de assistentes sociais e psicólogas em seu quadro de funcionárias; e a troca da defensora pública responsável pelo núcleo. Sobre este último ponto, é preciso destacar que as duas defensoras subsequentes também eram mulheres, o que reitera a ideia de que o lugar da coordenação de um núcleo como este deve ser ocupado por alguém que tenha "sensibilidade", "empatia" e "identificação com a causa".

2 O programa "Rio Sem Homofobia" foi criado em maio de 2007 com o objetivo de combater a discriminação e a violência contra a população LGBT e promover sua cidadania. Como parte do programa, foram inaugurados também em 2011 o primeiro dos Centros de Cidadania LGBT a entrar em funcionamento e o Disque Cidadania LGBT. Além de se configurar como um espaço de convivência e socialização, tais Centros realizavam também um trabalho de acolhimento de pessoas LGBT que sofreram violências e/ou estavam em situação de vulnerabilidade, serviço oferecido por assistentes sociais, psicólogos e advogados contratados pelo programa. Assim como outros serviços e políticas públicas estaduais, a partir do advento da crise econômica no Rio de Janeiro em meados de 2014, os Centros de Cidadania LGBT - e o próprio programa "Rio Sem Homofobia" - passaram por um intenso processo de sucateamento, tendo seu orçamento reduzido, funcionários com salários atrasados, suspensão de investimentos etc. Para pesquisas sobre o processo de construção e implementação do "Rio Sem Homofobia", consultar Aguião (2018) e Carrara et al. (2017). Para uma análise do processo de desmonte do programa, consultar Cassal (2018).

3 Além de posicionar o núcleo em uma das diferentes etapas de assistência jurídica prestada pela Defensoria Pública, a categoria "primeiro atendimento" caracteriza também um dos mais importantes momentos na trajetória de uma pessoa assistida pelo Nudiversis. É nessa situação que histórias, demandas e pessoas são avaliadas, podendo ou não gerar a "abertura de procedimento", movimento que significa a oficialização da recepção do pedido de requalificação civil. Os encontros entre assistidas/os e funcionárias nesse primeiro atendimento são marcados por uma série de tensões e conflitos - uns mais e outros menos explícitos - assim como por regras de registro que fazem com que as histórias narradas pelas/os usuárias/os sejam escutadas a partir de um roteiro único. Contudo, devido aos limites do que me proponho a discutir no artigo, este ponto não será aprofundado.

4 A discrepância entre o número de pessoas transexuais atendidas e a quantidade de petições iniciais elaboradas se devem ao fato de que nem todas elas conseguiram reunir todos os documentos para que a petição pudesse ser redigida. 
5 Como discuti em artigo anterior (Freire 2016), o avanço nas etapas dos procedimentos assistenciais do Nudiversis implica uma constante obliteração das singularidades de cada usuária/o, já que nem tudo que é dito durante o atendimento é considerado relevante o suficiente para ser anotado e documentado pelas profissionais no contexto de produção documental que embasará o pedido de requalificação civil. O auge - mas que também pode ser um ponto de partida, a depender do ângulo que se observa - desse processo, que chamei de "contração narrativa", é justamente a elaboração de um modelo para as petições iniciais de alteração do registro civil de pessoas transexuais, o que, em última instância, funciona para a construção de uma espécie de "homogeneidade experiencial" que cerca as vidas desses sujeitos.

6 Esta ambiguidade se torna mais evidente quando observamos as movimentações de atores sociais envolvidos na militância pelos direitos de pessoas transexuais no sentido de traçar linhas e delimitar o espaço das pessoas " $\mathrm{T}$ " no interior das políticas voltadas para a efetivação dos "direitos LGBT". De acordo com estes atores, as demandas de travestis e transexuais são radicalmente distintas das de lésbicas, gays e bissexuais na medida em que as primeiras têm como fonte a vivência de determinadas identidades de gênero, ao passo que as últimas se fundamentam no exercício da orientação sexual.

7 As informações contidas na seção "fundamentos fáticos" das petições iniciais são apoiadas e comprovadas por uma série de documentos que são anexados ao final da sua elaboração. Dentre estes, destaco os relatórios social e psicológico que compõem o Estudo Social feito por servidores da Defensoria Pública. Esses relatórios são feitos a partir de entrevistas e têm por objetivo confirmar não só as trajetórias dos indivíduos, mas também a condição de incessante sofrimento à qual as pessoas transexuais estão sujeitas por conta das experiências de discriminação vivenciadas, avaliando a procedência do pedido de requalificação civil da pessoa transexual. O papel desses distintos documentos na produção de sujeitos e mundos sociais (Vianna 2014) foi trabalhada por mim em artigo anterior (Freire 2016).

8 Os Ofícios de Registro de Distribuição (ORD) são órgãos extrajudiciais do Estado, fiscalizados pelo Poder Judiciário, encarregados de registrar diversos tipos de atos, documentos e títulos no município do Rio de Janeiro, bem como garantir a disponibilidade, a perpetuidade, a conservação e a autenticidade dos mesmos. Em outras palavras, os ORD são entidades que até a Constituição de 1988 eram chamadas de "cartórios" e realizam "serviços notariais", isto é, dão "fé pública" aos diversos tipos de documentos com que lidam. As "certidões de nada consta" emitidas por estes órgãos atestam a inexistência de registros em nome da/o assistida/o acerca de diversas questões judiciais, tais como ações criminais, execuções fiscais, protesto de títulos etc.

9 O Diagnostic and Statistical Manual of Mental Disorders (Manual Diagnóstico e Estatístico de Transtornos Mentais, ou DSM) é uma publicação da Associação Americana de Psiquiatria que define critérios diagnósticos para a categorização de transtornos mentais diversos. Seu alcance é amplo, sendo utilizado por boa parte dos profissionais de saúde mental, pesquisadores, companhias de seguro de saúde e indústrias farmacêuticas em vários lugares do mundo. 
10 A Classificação Internacional de Doenças e Problemas Relacionados à Saúde (CID) é uma publicação da Organização Mundial de Saúde (OMS) que visa estabelecer e padronizar a codificação de patologias em um âmbito global. É importante destacar que a $11^{a}$ edição da CID deslocou a transexualidade da seção sobre "doenças mentais" para "condições relacionadas à saúde sexual", inaugurando uma nova fase na luta pela despatologização das identidades trans.

\section{Referências bibliográficas}

AGUIÃO, Silvia. 2018. Fazer-se no

"Estado": uma etnografia sobre o processo de constituição dos "LGTB" como sujeitos de direitos no Brasil contemporâneo. Rio de Janeiro: EdUERJ.

ALEXANDRE, Juliana Ribeiro. 2015. Emoções, Documentos e Subjetivação na construção de transexualidades em João Pessoa/PB. Dissertação de Mestrado, Universidade Federal do Rio Grande do Norte.

ALMEIDA, Guilherme \& MURTA, Daniela. 2013. "Reflexões sobre a possibilidade de despatologização da transexualidade e a necessidade da assistência integral à saúde de transexuais no Brasil". Sexualidad, Salud y Sociedad, 14:380-407.

BAILEY, Frederick. 1983. The Tactical Uses of Passion: an essay on power, reason, and reality. London: Cornell University Press.

BENTO, Berenice. 2006. A Reinvenção do Corpo: sexualidade e gênero na experiência transexual. Rio de Janeiro: Garamond.

BESEN, Lucas Riboli. 2018. "Pode tudo, até ser CIS": Segredo de justiça, cisgeneridade e efeitos de estado a partir de uma peciagrafia dos processos de retificação do registro civil em Porto Alegre/RS. Tese de Doutorado, Universidade Federal do Rio Grande do Sul.

BOLTANSKI, Luc. 1990. El Amor y la Justicia como competencias: tres ensayos de la sociología de la acción. Buenos Aires: Amorrortu. . 1999. Distant Suffering: morality, media and politics. Cambridge: Cambridge University Press.

BORBA, Rodrigo. 2016. O (des) aprendizado de si: transexualidades, interação e cuidado em saúde. Rio de Janeiro: Ed. Fiocruz.

CARRARA, Sérgio. 2010. "Políticas e direitos sexuais no Brasil contemporâneo". Bagoas, 5:131-147.

CARRARA, Sérgio et al. 2017. Retratos da Política LGBT no Estado do Rio de Janeiro. Rio de Janeiro: Cepesc.

CASSAL, Luan. 2018. “Um estudo entre ruínas: O programa Rio sem homofobia e a política LGBT fluminense". Rebeh: Revista Brasileira de Estudos da Homocultura, 1 (4):124162.

COACCI, Thiago. 2020. "A queima dos laudos: controvérsias e reconfigurações dos saberes e direitos trans na ADI 4275". Direito e Práxis, 11 (22):1188-1210. 
FASSIN, Didier. 2012. Humanitarian Reason: a moral history of the present. Berkeley: University of California Press.

FASSIN, Didier \& RECHTMAN, Richard. 2009. The Empire of Trauma: an inquiry into the condition of victimhood. Princeton: Princeton University Press.

FONSECA, Claudia \& CARDARELLO, Andrea. 1999. "Direitos dos Mais e Menos Humanos". Horizontes Antropológicos, 10:83-121.

FREIRE, Lucas. 2016. "Sujeitos de papel: sobre a materialização de pessoas transexuais e a regulação do acesso a direitos". Cadernos Pagu, 48:1-34.

GARBER, Marjorie. 2004. "Compassion". In: L. Berlant (ed.), Compassion: the culture and politics of an emotion. New York: Routledge. pp. 15-28.

GLUCKMAN, Max. 1972. The Allocation of Responsibility. Manchester: Manchester University Press.

GREGORI, Maria Filomena. 1993. Cenas e Queixas: um estudo sobre mulheres, relações violentas e a prática feminista. São Paulo: Paz e Terra/Anpocs.

LEITE JR., Jorge. 2010. Nossos Corpos Também Mudam: a invenção das categorias "travesti" e "transexual" no discurso científico. São Paulo: Annablume/Fapesp.

LIMA, Luiza Ferreira. 2015. A "verdade" produzida nos autos: uma análise de decisões judiciais sobre retificação de registro civil de pessoas transexuais em Tribunais brasileiros. Dissertação de Mestrado, Universidade de São Paulo.

MAHMOOD, Saba. 2005. Politcs of Piety: the Islamic revival and the feminist subject. Princenton: Princenton University Press.
OLIVEIRA, Melissa Barbieri. 2017. Trans tornando o campo do direito: Uma análise da construção da categoria transexual na doutrina jurídica brasileira e seus efeitos no reconhecimento das pessoas trans como sujeito de direitos. Tese de Doutorado, Universidade Federal de Santa Catarina

PIMENTA, Luiza Cotta. 2020. Direito e transexualidades: a alteração de nomes, seus papéis e negociações. Dissertação de Mestrado, Universidade Federal de Juiz de Fora.

PINHEIRO, Tarcísio Dunga. 2016. Entre elas: políticas públicas e cidadania de travestis e mulheres transexuais de uma ONG em Natal/RN. Dissertação de Mestrado, Universidade Federal do Rio Grande do Norte.

REGO, Francisco Cleiton Vieira Silva. 2015. Viver e esperar viver: corpo e identidade na transição de gênero de homens trans. Dissertação de Mestrado, Universidade Federal do Rio Grande do Norte.

REZENDE, Claudia \& COELHO, Maria Claudia. 2010. Antropologia das Emoções. Rio de Janeiro: FGV.

SARTI, Cynthia. 2009. "Corpo, Violência e Saúde: a produção da vítima". Sexualidad, Salud y Sociedad, 1:89103.

2011. "A Vítima como Figura Contemporânea", Caderno CRH, 24 (61):51-61.

TEIXEIRA, Flavia. 2013. Dispositivos de Dor: saberes-poderes que (con) formam as transexualidades. São Paulo: Annablume/Fapesp.

VENTURA， Miriam. 2010 .A Transexualidade no Tribunal: saúde e cidadania. Rio de Janeiro: EdUERJ. 
VIANNA, Adriana. 2012. "Atos, Sujeitos e Enunciados Dissonantes: algumas notas sobre a construção dos direitos sexuais". In: R. Miskolci \& L. Pelúcio (orgs.), Discursos Fora da Ordem: sexualidades, saberes e direitos. São Paulo: Annablume. pp. 227-244.

. 2014. “Etnografando Documentos: uma antropóloga em meio a processos judicias". In: S. Castilho; A. C. Souza Lima \& C. C. Teixeira (orgs.), Antropologia das Práticas de Poder: reflexões etnográficas entre burocratas, elites e corporações. Rio de Janeiro: Contra Capa/Faperj. pp. 43-70.

WHITE, Geoffrey. 1990. "Moral discourse and the rhetoric of emotions". In: C. Lutz \& L. Abu-Lughod (eds.), Language and the Politics of Emotion. New York: Cambridge University Press. pp. 46-68.

WILLIAMS, Brackette. 1989. "A Class Act: anthropology and the race to nation across ethnic terrain". Annual Review of Anthropology, 18:401-444. ZAMBRANO, Elizabeth. 2005. "Mudança de nome no registro civil: a questão transexual". In: M. B. Ávila; A. P. Portella \& V. Ferreira (orgs.), Novas Legalidades e Democratização da Vida Social: família, sexualidade e aborto. Rio de Janeiro: Garamond. pp. 95-111. 
EM DEFESA DA DIGNIDADE: MORALIDADES E EMOÇÕES NAS DEMANDAS POR DIREITOS DE PESSOAS TRANSEXUAIS

\section{Resumo}

Este artigo traz uma análise do modelo de petição inicial de requalificação civil de pessoas transexuais elaborado pelas funcionárias do Núcleo de Defesa da Diversidade Sexual e Direitos Homoafetivos da Defensoria Pública do Estado do Rio de Janeiro e sua influência no cotidiano da instituição. Os dados aqui discutidos são oriundos da etnografia realizada no núcleo em 2014. O principal argumento apresentado para a efetivação do direito à alteração do nome e/ou sexo é a defesa da "dignidade da pessoa humana". Por um lado, parte da retórica utilizada nestes documentos tenta produzir no indivíduo responsável pelo julgamento uma empatia pelo autor da ação ao apelar para a compaixão. Por outro, há, ao longo do texto, denúncias de uma espécie de "contaminação moral" por parte dos juízes que negam tais pedidos, revelando dimensões morais e emocionais no fazer político de pessoas transexuais na busca pelos "seus direitos".

Palavras-chave: Dignid a d e, Moralidades, Direitos, Transexualidade, Requalificação civil.
IN DEFENSE OF DIGNITY: MORALS AND EMOTIONS IN TRANSGENDER PEOPLE'S DEMANDS FOR RIGHTS

\section{Abstract}

This paper analyses the model for a motion of civil requalification of transsexual people prepared by employees of the Center for the Defense of Sexual Diversity and "Homoaffecttive Rights" of the Public Defender's Office of the State of Rio de Janeiro, and its influence on the daily life of the institution. The data I discuss come from the ethnography carried out at this center during 2014. The main argument for realizing the right to change name and/ or sex is a defense of the "dignity of the human person". On the one hand, part of the rhetoric used in these documents tries to produce in the individual responsible for the judgment an empathy for the suitor by appealing to compassion. On the other hand, throughout the text, there are denunciations of a kind of "moral contamination" on the part of judges who deny such requests, revealing moral and emotional dimensions in the political making of transsexual people in search of "their rights".

Key Words: Dignity, Moralities, Rights, Transsexuality, Civil requalification. 


\section{EN DEFENSA DE LA DIGNIDAD: \\ MORALIDADES Y EMOCIONES EN \\ LAS DEM ANDAS POR DERECHOS DE PERSONAS TRANSEXUALES}

\section{Resumen}

En este artículo se analiza el modelo de petición inicial de rectificación de nombre y género de personas transexuales elaborado por las empleadas del Núcleo de Defensa de la Diversidad Sexual y los Derechos Homoafectivos de la Defensoría Pública del Estado de Río de Janeiro, así como su influencia en la vida diaria de la institución. Los datos que aquí se discuten provienen de una etnografía realizada en este núcleo en 2014. El principal argumento que se presenta para hacer efectivo el derecho a la alteración del nombre y/o del sexo es la defensa por la "dignidad humana". Por un lado, parte de la retórica utilizada en estos documentos intenta producir en el individuo responsable por el juicio, una empatía por el autor de la acción al apelar a la compasión. Por el otro, hay, a lo largo del texto, denuncias de una especie de "contaminación moral" por parte de los jueces que niegan estos pedidos, revelando dimensiones morales y emocionales en el quehacer político de las personas transexuales en la búsqueda por "sus derechos".

Palabras clave: Dignidad, Moralidades, Derechos, Transexualidad, Rectificación civil. 